\title{
Naval Approach for Grid Connected PV Inverters Using PID Controller
}

\author{
${ }^{1} \mathrm{R}$. Sivakumar and ${ }^{2} \mathrm{~T}$. Rajamanikandan \\ ${ }^{1}$ Department of Electrical and Electronics Engineering, \\ SRS Engineering College, Salem, Tamil Nadu, India \\ ${ }^{2}$ Department of Electrical and Electronics Engineering, \\ Kongunadu College of Engineering and Technology, Trichy, Tamil Nadu, India
}

\begin{abstract}
The DC/AC inverters are used in grid-connected PV energy production systems as the power processing interface between the PV energy source and the electric grid. The energy injected into the electric grid by the PV installation depends on the amount of power extracted from the PV power source and the efficient processing of this power by the DC/AC inverter. In this study, two new methods are presented for the optimal design of a PV inverter power section, output filter and MPPT control strategy. The influences of the electric grid regulations and standards as well as the PV array operational characteristics on the design of grid-connected PV inverters have been considered. The proposed methods have been applied for the optimal design of PV inverters installed at various sites in Europe. The simulation results verify that the proposed optimization techniques enable the maximization of the PV energy injected into the electric grid thus, serving as a tool to gain more energy by the optimized PV installation.
\end{abstract}

Key words: Photovoltaic power systems, DC-AC power conversion, design methodology, optimization methods, standard installation

\section{INTRODUCTION}

The DC/AC inverters are used in grid connected Photovoltaic (PV) energy production systems as the power processing interface between the PV power source and the electric grid. Compared to the grid-connected PV inverters that have galvanic isolation (either on the DC or the $\mathrm{AC}$ side), the transformer less PV inverters have the advantages of lower cost, higher efficiency, smaller size and lower weight (Kerekes et al., 2011). The galvanic isolation provides enhanced safety features but the necessity for its implementation depends on the electric grid codes imposed by the utility companies in each country (Araujo et al., 2010).

The general block diagram of a grid-connected PV System is showed in Fig. 1. The power section of the $\mathrm{DC} / \mathrm{AC}$ inverter consists of power switches controlled by a control unit. The $\mathrm{H}$ bridge, single-phase with DC decoupling, refu solar, H5, HERIC, NPC, conergy, $\mathrm{H}$-bridge zero vector rectifier, 3-phase full bridge and full bridge with split capacitor topologies are widely applied in order to built the power section of transformer less PV inverters since, they obtain the highest efficiency (Kerekes et al., 2011; Vazquez et al., 2009; Xiao et al., 2011; Blaabjerg et al., 2010). In order to increase the PV inverter power density, LCL-type output filters are usually

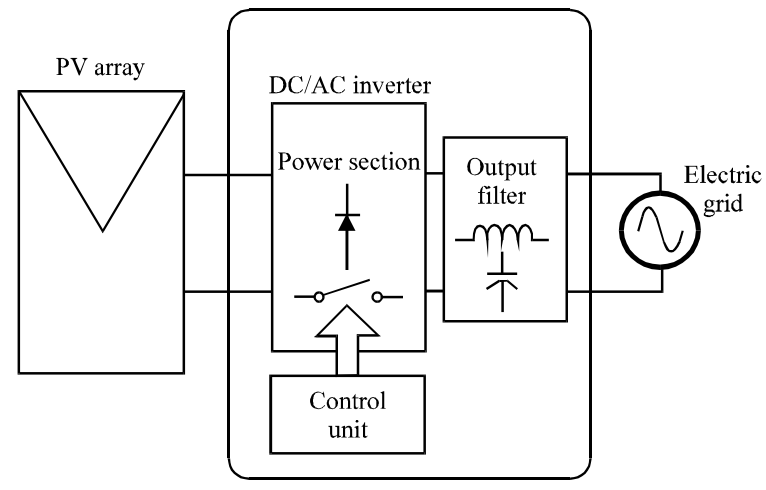

Fig. 1: The block diagram of a grid-connected PV System

used instead of the L- or LC-type filters (Figueres et al., 2009). The control unit is usually developed using DSP and FPGA ICs (Guerrero et al., 2010; Cecati et al., 2010) for the execution of control and energy management algorithms (e.g., Maximum Power Point Tracking (MPPT) (Patel and Agarwal, 2009), detection of islanding conditions, modulation strategies, etc.).

The PWM schemes used to control the power switches of transformer less PV inverters are typically based on the comparison of a low frequency reference sine-wave with a high frequency triangular wave

Corresponding Author: R. Sivakumar, Department of Electrical and Electronics Engineering, SRS Engineering College, Salem, Tamil Nadu, India 
(Floricau et al., 2009). Targeting at the minimization of the power switches losses (conduction and switching) and the equal distribution of these losses among the power switches or the minimization of the output voltage Total Harmonic Distortion (THD), various PWM strategies for NPC and active NPC inverters are investigated (Floricau et al., 2009; Ma et al., 2009; Rahim and Selvaraj, 2010; Pulikanti et al., 2008).

Various international standards (IEEE 1547, EN50160, etc.) set limitations on parameters such as the Total Demand Distortion (TDD\%) of the current injected at the PCC and the corresponding limits of the individual harmonics, the maximum values of the voltage harmonic distortion, voltage unbalance, voltage amplitude variations and frequency variations and the maximum permitted DC current injection.

These limitations must be considered during the design of PV inverters (Figueres et al., 2009; Kjaer et al., 2005). Metrics such as the power conversion efficiency and the European efficiency are used to evaluate the performance of the designed PV inverter (Kerekes et al., 2008; Vazquez et al., 2009).

The PV inverter operating efficiency depends on the power section topology and the type and operational characteristics (conducting and switching) of the components (semiconductors, agnetic elements and capacitors) which are used to build the PV inverter (Kerekes et al., 2008; Xiao et al., 2011). Typically, the PV inverter efficiency is reduced by $0.3-1 \%$ per $150 \mathrm{~V}$ of DC input voltage amplitude.

Additionally, it drops by up to $5 \%$ at light load and high DC input voltage (Giesler, 2010), due to the domination of the control unit and switching power losses during these operating conditions. Currently, the state of the art transformer less PV inverters have maximum power conversion efficiency and European efficiency values (at the nominal DC input voltage) in the order of 98 and $97 \%$, respectively.

The PV inverters are typically designed to operate over a wide DC input voltage range (350-750 V) in order to perform the PV array, MPPT process under the continuously varying solar irradiation and ambient temperature.

The power injected into the grid, the PV inverter power loss and the PV inverter efficiency under MPPT conditions during the same summer day for a commercial PV inverter installed in Athens (Greece), Murcia (Spain) and Freiburg (Germany), respectively are shown in Fig. 2. The corresponding power conversion efficiency of the PV inverter during the same day is showed in Fig. 3. It is
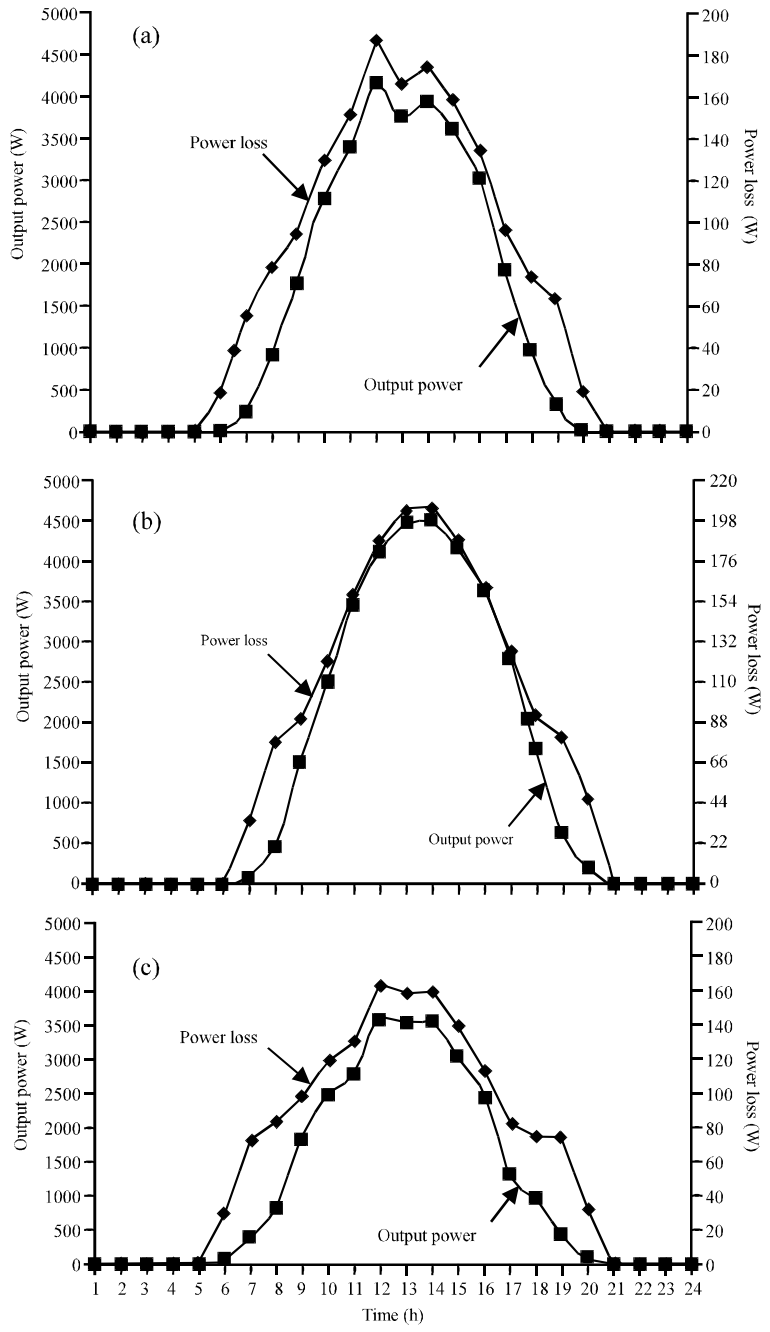

Fig. 2: The output power and power loss variations under MPPT conditions during the same summer day for a commercially available PV inverter installed in; a) Athens (Greece); b) Murcia (Spain) and c) Freiburg (Germany)

observed that in all cases considered both the power injected into the grid and the PV inverter power loss vary significantly during the day although, the corresponding power conversion efficiency of the PV inverter remains relatively constant.

The stochastically varying meteorological conditions prevailing at the PV array installation site and the effectiveness of the MPPT control strategy performed by the PV inverter control unit define the amount of power extracted from the PV power source. The actual energy injected into the electric grid depends on the efficient processing of this power by the PV inverter according to the shape of the PV inverter efficiency vs. output power curve. The objective of a power converter design 


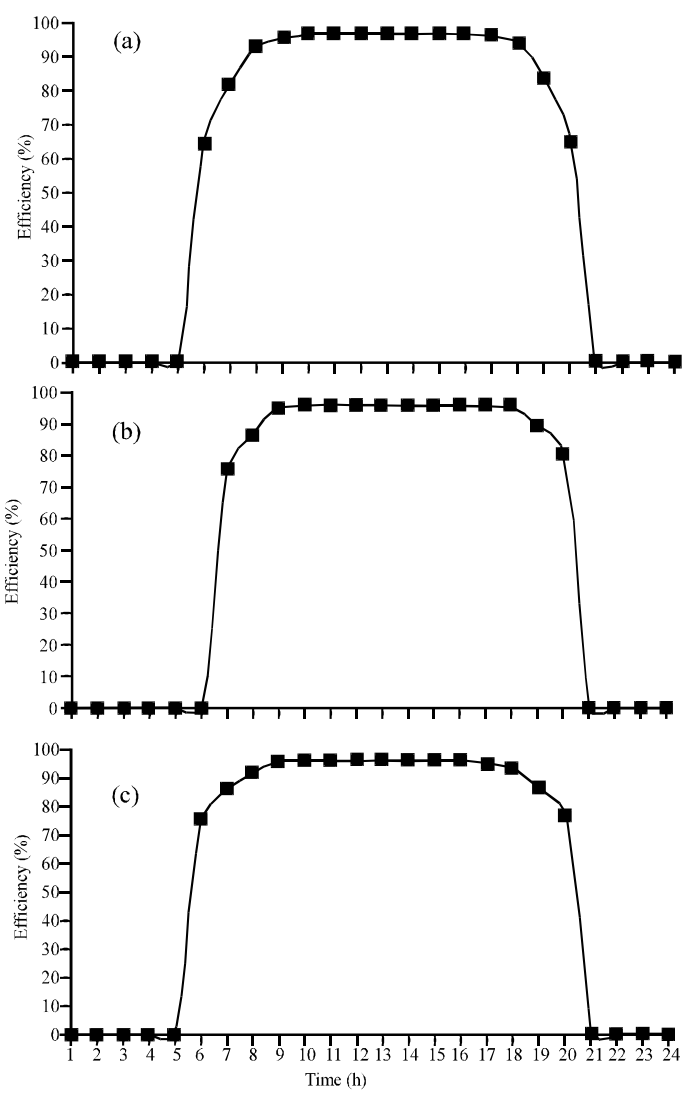

Fig. 3: The variation of the power conversion efficiency under MPPT conditions during the same summer day for a commercially available PV inverter installed in; a) Athens (Greece); b) Murcia (Spain) and c) Freiburg (Germany)

optimization procedure is given the converter topology to calculate the converter component types, values and dimensions which result in the minimization (or maximization, depending on its nature) of a certain converter characteristic defined by the designer (power loss, power density, etc.) while simultaneously, the performance specifications are met (Balachandran and Lee, 1981; Koutroulis and Blaabjerg, 2011).

Using these techniques, power density increments by a factor of 2-4 (Biela et al., 2009), reduction of the packaged power converter volume by $38.3 \%$ (Neugebauer and Perreault, 2003) and efficiency improvements in the order of $8-20 \%$ in the light to medium load region (Parayandeh et al., 2009) have been achieved. However, none of these methods has yet been applied for the design optimization of PV inverters. In this study, two new design optimization methods of PV inverters are presented for the optimal design of the PV inverter power section, output filter and MPPT control

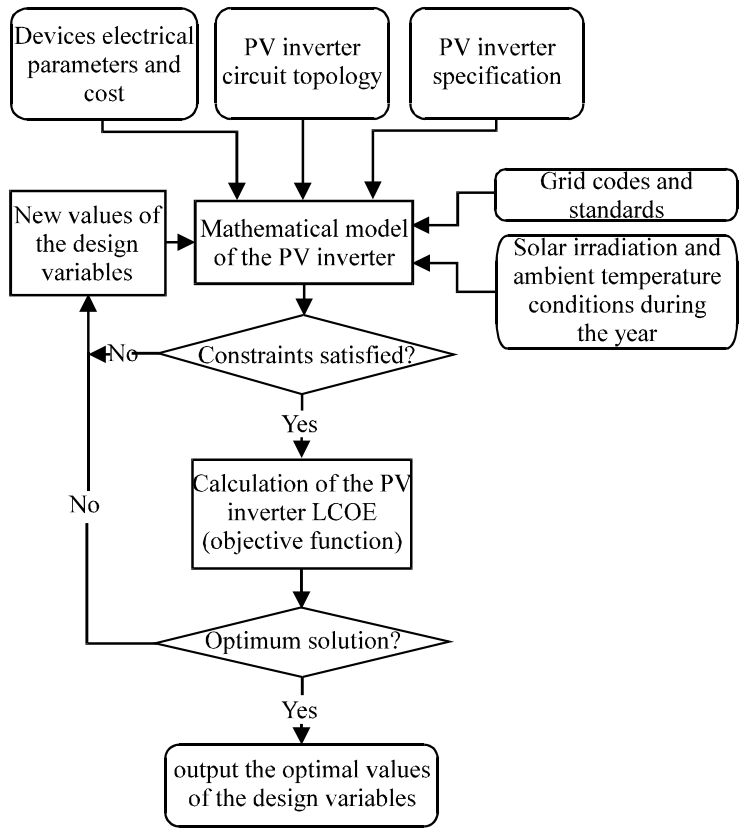

Fig. 4: The flow-chart of the proposed optimization procedure

strategy, respectively. The proposed techniques target to exploit the potential of non-linear optimization methods using multiple decision variables together with linear and non-linear constraints for the design of PV inverters. The optimization objective is to maximize the energy injected into the electric grid by the PV inverter with the minimum possible PV inverter construction and maintenance costs during its lifetime operation. This issue is explored for the first time in the existing literature. The proposed techniques encompass the influences of the electric grid regulations and standards as well as the PV array operational characteristics on the design of gridconnected PV inverters.

\section{MATERIALS AND METHODS}

The proposed design optimization methods of PV inverters

Power section and output filter: A flow-chart of the proposed automated optimization procedure is showed in Fig. 4. The optimization algorithm inputs are the following: $\varnothing$ operational characteristics (power rating, open-circuit voltage, etc.) of the PV modules and their configuration in the PV array (tilt angle, number of modules connected in series, etc.), $\varnothing 1 \mathrm{~min}$ or $1 \mathrm{~h}$ average solar irradiance and ambient temperature time-series during the year, $\varnothing$ input/output voltage ranges and the power rating 
specifications of the PV inverter, $\varnothing \mathrm{PV}$ inverter topology and modulation strategy, $\varnothing$ price and device-specific characteristics available in the device datasheet which define the switching and conducting behaviour of the power semiconductors used to built the inverter, $\varnothing$ price and technical characteristics of commercially available magnetic components and capacitors (in the format available in the device datasheet) for the construction of the output filter, $\varnothing$ grid-interconnection specifications (the maximum permitted harmonic current levels, etc.) imposed by grid codes and international standards, $\varnothing$ economic parameters (annual inflation rate, etc.).

The proposed design optimization algorithm calculates the optimal values of the following design (decision) variables; $\varnothing$ switching frequency, $\varnothing$ power semiconductors type and configuration (e.g., the number of power MOSFETS connected in parallel), $\varnothing$ power switches gate-drive design parameters such as the gate series resistances during turn-on and -off and the gatedrive supply voltage, $\varnothing$ output filter inductance and capacitance values (depending on the filter type), $\varnothing$ output filter inductor magnetic core size (center-eg width and window width), flux density, current density, copper size and number of turns, $\varnothing$ heat sink dimensions and thermal resistance to the ambient.

Given the PV inverter specifications and the available components electric, magnetic and thermal characteristics, the objective function minimization process is performed by iteratively producing new sets of the design variables values and evaluating the objective function until convergence to the optimum solution is detected. This procedure is performed using Genetic Algorithms which are capable to derive the global optimum solution of the objective function with relative computational simplicity. For each set of the design variables values, the satisfaction of the PV inverter operational constraints is verified using the appropriate mathematical models of the $\mathrm{PV}$ inverter topology under consideration.

The optimal values of the design variables are calculated such that the PV inverter Levelized Cost of the Electricity generated, LCOE ( $€ / W h)$ is minimized:

$$
\underset{X}{\operatorname{Minimize}}\{\operatorname{LCOE}(X)\}=\underset{X}{\operatorname{Minimize}}\left\{\frac{C_{t}(X)}{E_{t}(X)}\right\}
$$

Subject to:

Design specifications and constraints are met

Where:

$\mathrm{C}_{\mathrm{t}}(€)=$ The PV inverter total cost during its operational lifetime period
$E_{t}(W h)=$ The total energy which is injected into the electric grid by the PV inverter during its operational lifetime period

$\mathrm{X}=$ The vector of the design variables

The LCOE minimization process is performed subject to the constraints imposed by the PV inverter specifications and the grid codes and international standards. The LCOE objective function targets to maximize the PV inverter output energy by minimizing the $\mathrm{PV}$ inverter total energy losses arising due to the power losses of the PV inverter components while simultaneously, the minimum PV inverter cost is achieved. The LCOE is used as a metric in order to compare the relative cost of electricity among alternative electric energy production solutions (Campbell et al., 2009). The total energy which is injected into the electric grid by the $\mathrm{PV}$ inverter during its operational lifetime period, $\mathrm{E}_{\mathrm{t}}(\mathrm{Wh})$ is calculated as follows:

$$
E_{t}=\sum_{y=1}^{n} \sum_{t=1}^{8760} P_{0}(t, y) \cdot \Delta t
$$

Where:

$\mathrm{n}$ (years) $\quad=\mathrm{PV}$ inverter operational lifetime period

$\mathrm{P}_{0}(\mathrm{t}, \mathrm{y})(\mathrm{W})=$ The power injected into the grid by the $\mathrm{PV}$ inverter at hour t $(1 £ t £ 8760)$ of year $1 £ y £ n$

$\Delta \mathrm{t}=$ The simulation time-step set to $\Delta \mathrm{t}=1 \mathrm{~h}$

The types and values of the PV inverter components determine the PV inverter reliability characteristics and affect the PV inverter maintenance cost and total energy production during its lifetime period. Thus in the proposed methodology, the PV inverter failure and repair rates are calculated for each set of the design variables values $\mathrm{X}$ according to the analysis presented by Ristow et al. (2008). Then, the power injected into the grid by the PV inverter at hour $\mathrm{t}(1 £ \mathrm{t} £ 8760)$ of year $1 £ y £ n$ is calculated from the powerbalance equation as follows:

$$
P_{0}(t, y)=\left\{\begin{array}{l}
0, \text { during repair } \\
P_{p v, t}-P_{t o t, t}, \text { else }
\end{array}\right.
$$

Where:

$\mathrm{P}_{\mathrm{p}, \mathrm{t}}(\mathrm{W})=\mathrm{PV}$ array output power at hour $\mathrm{t}$ which is also equal to the $\mathrm{PV}$ inverter input power

$\mathrm{P}_{\text {tot } \mathrm{t}} \quad=\mathrm{PV}$ inverter total power loss at hour $\mathrm{t}$

In order to calculate the PV array output power $\mathrm{P}_{\mathrm{pv}}$, to it is assumed that an MPPT process is performed by the $\mathrm{PV}$ inverter control unit such that the maximum PV power is supplied to the PV inverter. The value of $P_{p v} t$ is calculated using the PV Modules Model analyzed in Lorenzo (1994) based on the solar irradiation and ambient 
temperature timeseries, the electrical specifications of the PV modules and their configuration (i.e., connection in series and parallel) within the PV array which are input in the proposed optimization procedure by the PV inverter designer. The PV inverter total power loss $\mathrm{P}_{\text {tot, } t}(\mathrm{~W})$ is equal to the sum of the power switches conduction and switching losses $\mathrm{P}_{\text {cond }}(\mathrm{W})$ and $\mathrm{P}_{\mathrm{sw}}(\mathrm{W})$, respectively the power loss on the output filter, $\mathrm{P}_{d}(\mathrm{~W})$ and the control unit power consumption (due to the circuits of the SPWM modulator, IGBT drivers, sensors and signal conditioners, etc.), $\mathrm{P}_{\mathrm{cu}}(\mathrm{W})$ :

$$
\mathrm{P}_{\mathrm{tot}, \mathrm{t}}=\mathrm{P}_{\mathrm{cond}}+\mathrm{P}_{\mathrm{sw}}+\mathrm{P}_{\mathrm{d}}+\mathrm{P}_{\mathrm{cu}}
$$

The PV inverter total cost $C_{t}(€)$ is calculated as the sum of the manufacturing cost and the maintenance cost during its operational lifetime period. The PV inverter total manufacturing cost is equal to the sum of the prices of the components comprising the PV inverter. The maintenance cost is estimated based on the PV inverter failure rate which is calculated by performing the reliability analysis.

Control strategy: The control unit of the PV inverter performs an MPPT function continuously in order to maximize the energy generated by the PV array. The MPPT schemes applied are based on the attributes of the PV array current-voltage characteristic. This leads to PV inverter operation at variable DC input voltage and power levels depending on the solar irradiation and ambient temperature conditions. The PV inverter efficiency $n_{\text {inv }}(\%)$ varies accordingly:

$$
\mathrm{n}_{\text {inv }}=\frac{\mathrm{P}_{\text {grid }}}{\mathrm{P}_{\mathrm{pv}}}=\mathrm{g}\left(\mathrm{P}_{\mathrm{pv}}, \mathrm{V}_{\mathrm{pc}}\right)=\mathrm{g}\left(\mathrm{f}\left(\mathrm{V}_{\mathrm{pv}}, \mathrm{G}, \mathrm{T}_{\mathrm{A}}\right), \mathrm{V}_{\mathrm{pv}}\right)
$$

Where:

$\mathrm{P}_{\text {grid }}(\mathrm{W}) \quad=\mathrm{PV}$ inverter output power

$\mathrm{P}_{\mathrm{pv}}(\mathrm{W})$ and $\mathrm{V}_{\mathrm{pv}}(\mathrm{V})=$ the $\mathrm{PV}$ array output power and voltage, respectively

$\mathrm{G}\left(\mathrm{W} \mathrm{m}^{-2}\right) \quad=$ The solar irradiance

$\mathrm{T}_{\mathrm{A}}\left({ }^{\circ} \mathrm{C}\right)=$ The ambient temperature

Thus, the PV inverter output power which is injected to the electric grid is calculated as follows:

$$
\begin{aligned}
P_{\text {grid }} & =g\left(f\left(V_{p v}, G, T_{A}\right), V_{p v}\right) \cdot P_{p v} \\
& =g\left(f\left(V_{p v}, G, T_{A}\right), V_{p v}\right) \cdot f\left(V_{p v}, G, T_{A}\right) \\
& =h\left(V_{p v}, G, T_{A}\right)
\end{aligned}
$$

It is observed that the power injected into the electric grid depends on the PV array output voltage, the solar irradiance and the ambient temperature. The application of a conventional MPPT scheme (Patel and Agarwal, 2009) on the PV array power-voltage characteristic depicted in

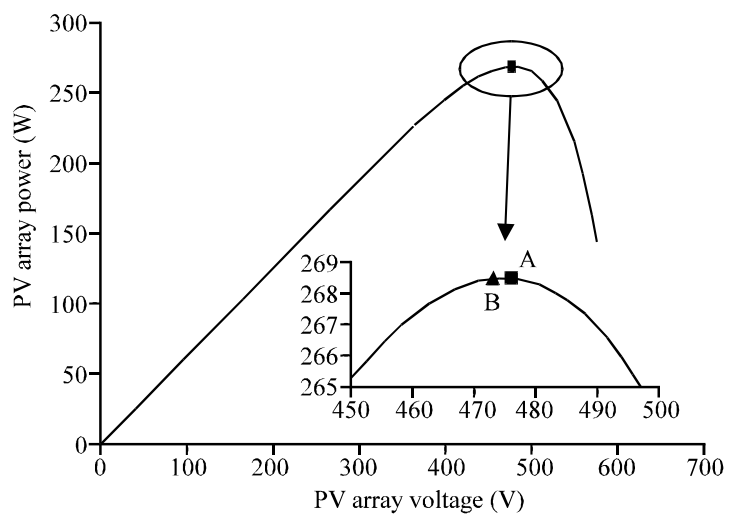

Fig. 5: The power-voltage characteristic of a PV array for MPPT operation

Fig. 5, results in the $\mathrm{PV}$ array operation at point $\mathrm{A}$. However, due to the PV inverter power conversion efficiency characteristics, the power injected by the PV inverter into the electric grid is maximized at point $\mathrm{B}$. In order to operate the PV array under the stochastically varying meteorological conditions at the point where the power injected into the electric grid is maximized (i.e., point B in Fig. 5), the MPPT process implemented in the control unit of the PV inverter (Kerekes et al., 2011) can be performed using a Perturb and Observe algorithm according to the following control law:

$$
\begin{aligned}
& \mathrm{c}_{\mathrm{s}, \mathrm{k}}=\mathrm{c}_{\mathrm{s}, \mathrm{k}-1}+\Delta \mathrm{c}_{\mathrm{s}, \mathrm{k}-1} \\
& \Delta \mathrm{c}_{\mathrm{s}, \mathrm{k}-1}=\mathrm{C} \cdot \operatorname{sign}\left(\Delta \mathrm{c}_{\mathrm{s}, \mathrm{k}-2}\right) \cdot \operatorname{sign}\left(\frac{\mathrm{P}_{\mathrm{grid}, \mathrm{k}-1}-\mathrm{P}_{\mathrm{grid}, \mathrm{k}-2}}{\mathrm{~V}_{\mathrm{pv}, \mathrm{k}-1}-\mathrm{V}_{\mathrm{pv}, \mathrm{k}-2}}\right)
\end{aligned}
$$

Where, $\Delta \mathrm{c}_{\mathrm{s}, \mathrm{k}-1}$ is the control signal (reference voltage, reference current, etc.) change at step $\mathrm{k}-1, \mathrm{P}_{\text {grid, } \mathrm{k}-1}$ and $\mathrm{P}_{\text {grid, } \mathrm{k}-2}$ are the PV inverter output power levels at steps k-1 and $\mathrm{k}-2$, respectively. $\mathrm{C}$ is a constant determining the speed and accuracy of convergence to the MPP point and the function $\operatorname{sign}(\mathrm{x})$ is defined as:

$$
\operatorname{Sign}(x)= \begin{cases}1 & \text { if } x \geq 0 \\ -1 & \text { if } x<0\end{cases}
$$

The proposed method does not increase the PV inverter cost since, the sensors and signal conditioning circuits required to measure $\mathrm{P}_{\text {gid }}$ and $\mathrm{V}_{\mathrm{pv}}$ are also installed in the PV inverter control unit in order to implement the conventional control schemes of the PV inverters.

\section{RESULTS AND DISCUSSION}

Design examples: The PV inverter design optimization methodology has been applied for the optimal design of a single-phase, full-bridge grid-connected SPWM PV 
inverter (Fig. 6) comprised of IGBT-type power switches with anti-parallel diodes and an LCL-type output filter. The PV inverter nominal output power and voltage ratings are $=2000 \mathrm{~W} \mathrm{P}_{\mathrm{n}}$ and $=220 \mathrm{~V} \mathrm{~V}_{\mathrm{n}}$ respectively. The PV inverter is connected to a PV array composed of $12 \mathrm{PV}$ modules connected in series. The MPP power and voltage ratings of each PV module under Standard Test Conditions (STC) are $175 \mathrm{~W}$ and $35.4 \mathrm{~V}$, respectively. The optimization problem design (decision) variables considered during the GA optimal sizing procedure are the PV inverter switching frequency and the LCL output filter components values. Thus, each GA consists of four genes in the form:

$$
\mathrm{X}_{\mathrm{gfs}}=[\mathrm{LCL} / \mathrm{f}]
$$

After the GA-based optimization process has been accomplished, the optimal value of the LCL filter damping resistor $R_{d r}$ is calculated using the resulting optimal values of L , $\mathrm{L}_{\mathrm{g}}$ and $\mathrm{C}_{\mathrm{f}}$ as analyzed in (Liserre et al., 2005). The PV inverter maintenance cost has not been considered in this design example. The values of $\mathrm{P}_{\text {cond }}$ and $\mathrm{P}_{s w}$ have been calculated using the power loss model presented in (Pattnaik and Mahapatra, 2010).

Since, the power switches of the PV inverter under consideration are controlled according to the Sinusoidal Pulse Width Modulation (SPWM) principle (Nge et al., 2009), the $P V$ inverter switching frequency, $f_{s}(H z)$ is constrained to be an integer multiple of the grid frequency $\mathrm{f}(\mathrm{Hz})$. Additionally, the maximum possible value of $f_{s}$ is dictated by the maximum switching speed capability of the power switches $\mathrm{f}_{s, \max }(\mathrm{Hz})$, specified by their manufacturer:

$$
\mathrm{f}_{s} \leq \mathrm{f}_{s, \max }
$$

The LCL-type output filter components values are calculated by the optimization algorithm such that the current ripple at the PV inverter output is below the maximum permissible limit which is imposed by the grid regulations and standards as analyzed by Liserre et al.

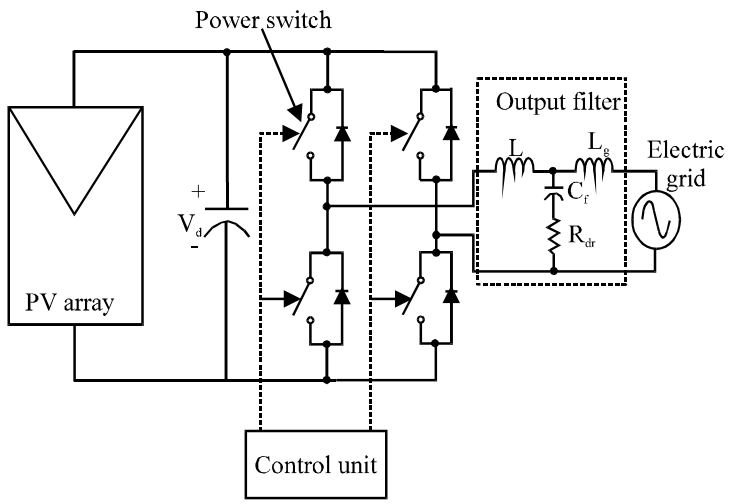

Fig. 6: The block diagram of a grid-connected, singlephase
(2005). The proposed Optimal Design Method has been implemented in the form of a properly developed software program operating under the Matlab platform. The Genetic Algorithm functions available in the Matlab global optimization toolbox have been used in order to derive the global minimum of the PV inverter LCOE (objective) function. In order to demonstrate an example of the optimization problem search space, the variation of the yearly energy injected into the grid, the PV inverter total cost and the LCOE for various values of the decision variables $L$ and $f_{s}$ in case that the $P V$ inverter is installed in Athens (Greece) and $=153.6 \mu \mathrm{H} \mathrm{L}_{\mathrm{g}}$ and $=6.570 \mu \mathrm{F} \mathrm{C}_{\mathrm{f}}$ are shown in Fig. 7.
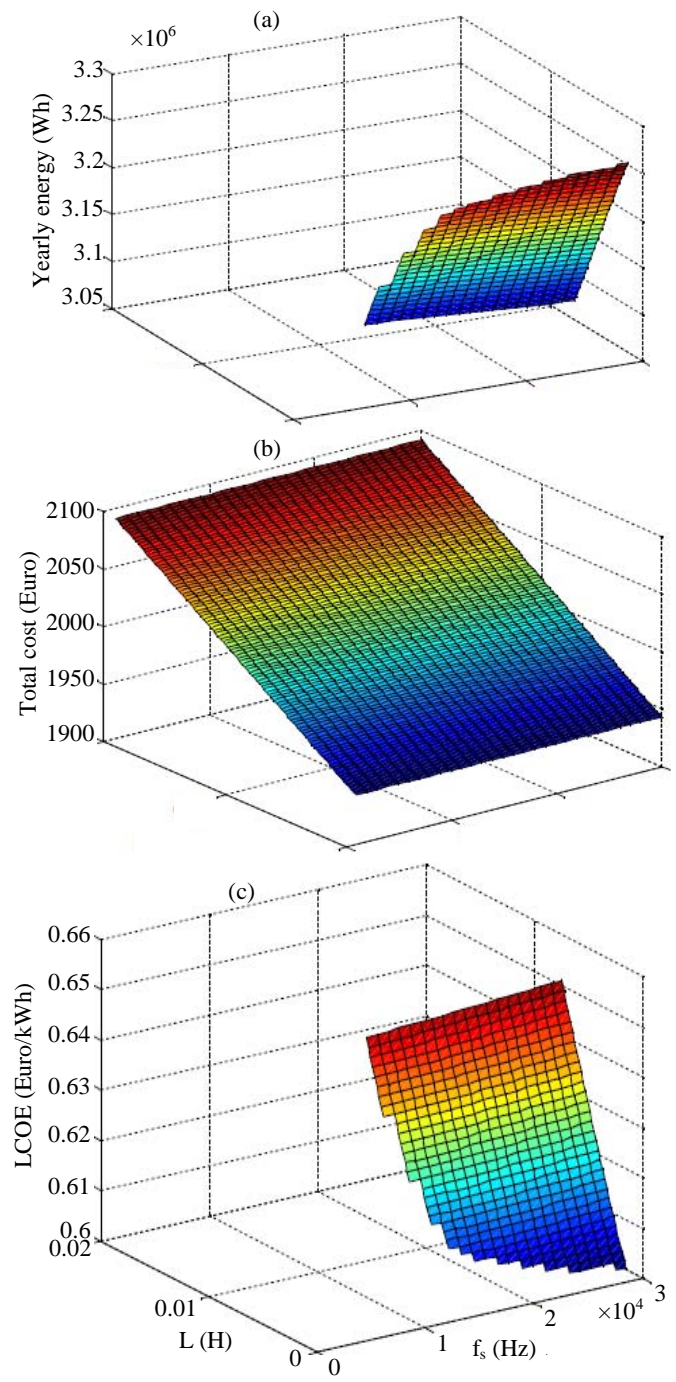

Fig. 7: The yearly energy injected into the grid: a) the PV inverter total cost; b) and the LCOE and c) for various values of the decision variables $L$ and $f_{s}$ in case that the PV inverter is installed in Athens (Greece) and $=153.6 \mu \mathrm{H} \mathrm{L}_{\mathrm{g}}$ and $=6.570 \mu \mathrm{F} \mathrm{C}_{\mathrm{f}}$ 
The yearly energy injected into the grid, the PV inverter total cost and the LCOE for various values of the decision variables $\mathrm{L}_{\mathrm{g}}$ and $\mathrm{C}_{\mathrm{f}}$ in case that the $\mathrm{PV}$ inverter is installed in Athens (Greece) and $\mathrm{L}=1.418 \mathrm{mH}$ and $=29.95$ $\mathrm{kHz} \mathrm{f}_{\mathrm{s}}$ are shown in Fig. 8. Figure 7 and 8 have been constructed using only the values of $\mathrm{L}, \mathrm{L}_{\mathrm{g}}, \mathrm{C}_{\mathrm{f}}$ and $\mathrm{f}_{\mathrm{s}}$ which satisfy the optimization problem constraints. It is observed that the LCOE function is highly non-linear thus, dictating the use of a computationally efficient optimization algorithm such as GAs in order to derive the global optimum values of $\mathrm{L}, \mathrm{L}_{\mathrm{g}} \mathrm{C}_{\mathrm{f}}$ and $\mathrm{f}_{\mathrm{s}}$ which minimize the value of LCOE. For the application example showed in Fig. 7 and 8, the $\mathrm{LCOE}$ is minimized for $\mathrm{L}=1.418 \mathrm{mH}$, $153.6 \mu \mathrm{H} \mathrm{L} \mathrm{L}_{\mathrm{g}}=6.570 \mu \mathrm{F} \mathrm{C}_{\mathrm{f}}$ and $=29.95 \mathrm{kHz}_{\mathrm{s}}$ resulting in
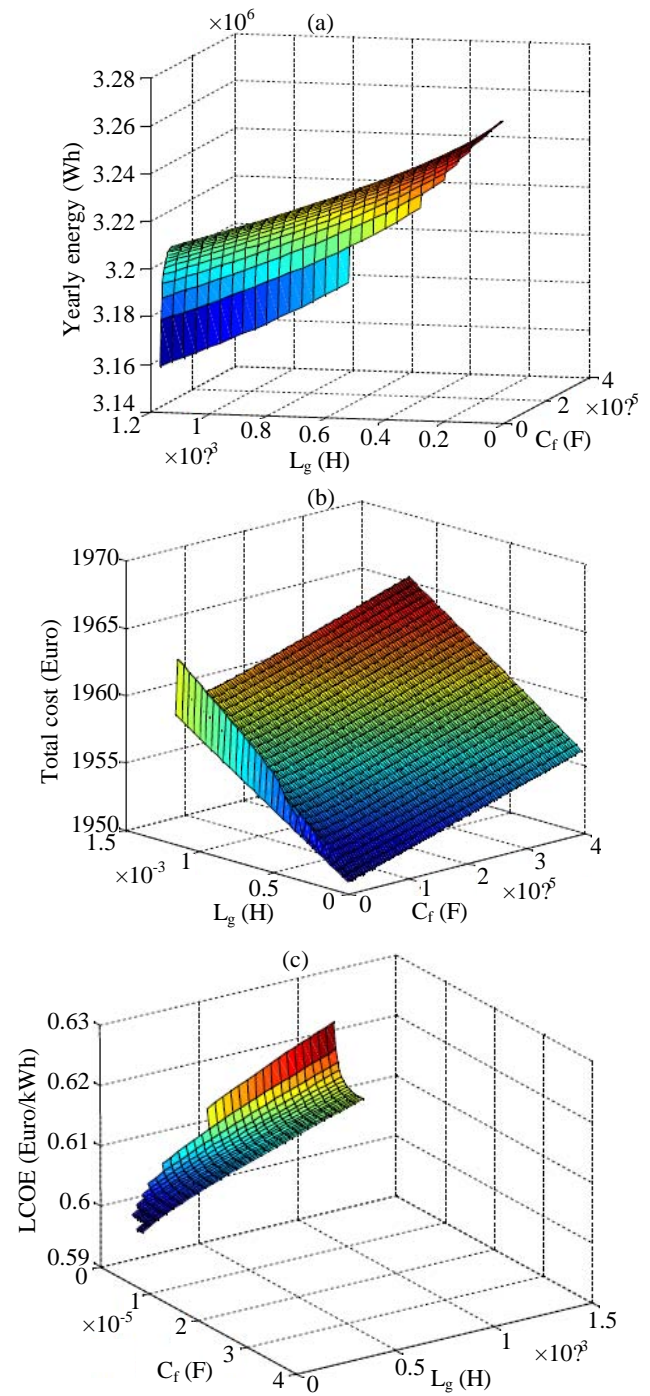

Fig. 8: The yearly energy injected into the grid; a) the PV inverter total cost; b) LCOE and c) for various values of the decision variables $\mathrm{L}_{\mathrm{g}}$ and $\mathrm{C}_{\mathrm{f}}$ in case that the PV inverter is installed in Athens (Greece) and $\mathrm{L}=1.418 \mathrm{mH}$ and $=29.95 \mathrm{kHz} \mathrm{f}_{\mathrm{s}}$
$\mathrm{LCOE}=0.6 € / \mathrm{kWh}, \mathrm{t}=1952.9 € \mathrm{C}$ and $\mathrm{t}=3.255 \mathrm{Mwh} \mathrm{E}$. The proposed method has also been applied for the optimal design of PV inverters installed in Murcia (Spain) and Freiburg (Germany). A different set of optimal values of the PV inverter output filter components values is derived in each case, since each of these sites is characterized by a different solar irradiation potential. Additionally, the resulting optimal $\mathrm{LCOE}$ values differ by $-11.5 \%$ (Murcia, Spain) and $+45 \%$ (Freiburg, Germany), respectively, compared to the optimal $\mathrm{LCOE}$ of the PV inverter installed in Athens (Greece). These results indicate the geographical variability of the PV inverter components optimal values which achieve the optimal (minimum) LCOE for each installation site. In order to evaluate the performance of the proposed MPPT Method, the operation of a commercially available PV inverter with galvanic isolation and a transformerless PV inverter has been simulated using a properly developed software program operating under the Matlab platform. The power conversion efficiency and MPP voltage range specifications provided by the manufacturer of these PV inverters have been incorporated in the simulation algorithm. The increment of the hourly energy injected into the grid which is achieved using the proposed MPPT
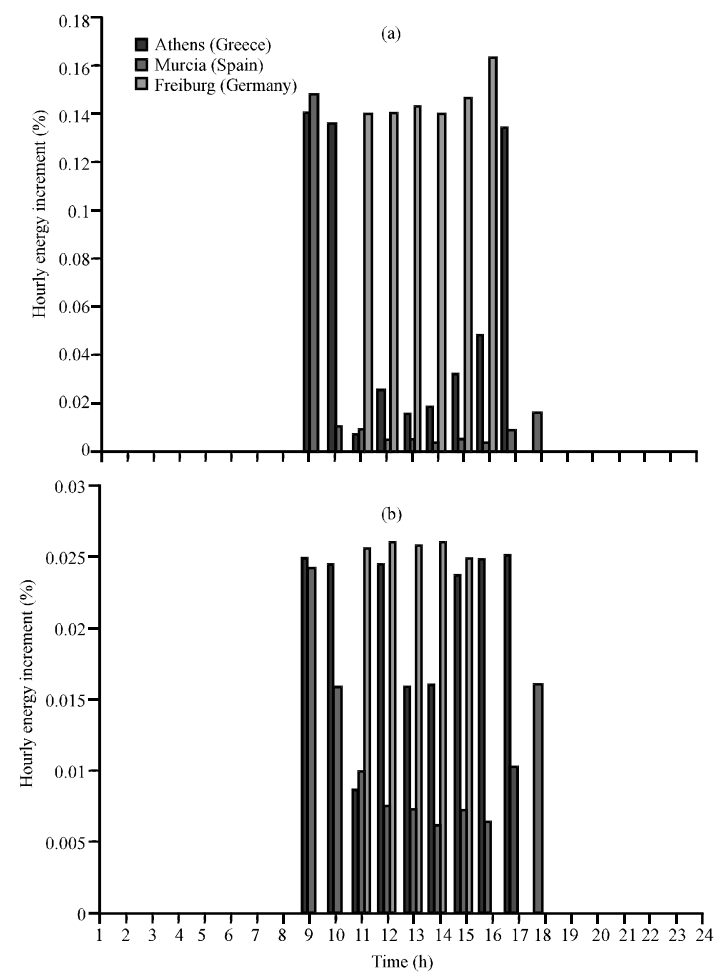

Fig. 9: The increment of the hourly energy injected into the grid by applying the proposed MPPT Method during a Winter day at various sites in Europe for; a) a PV inverter with galvanic isolation and b) a transformer less PV inverter 


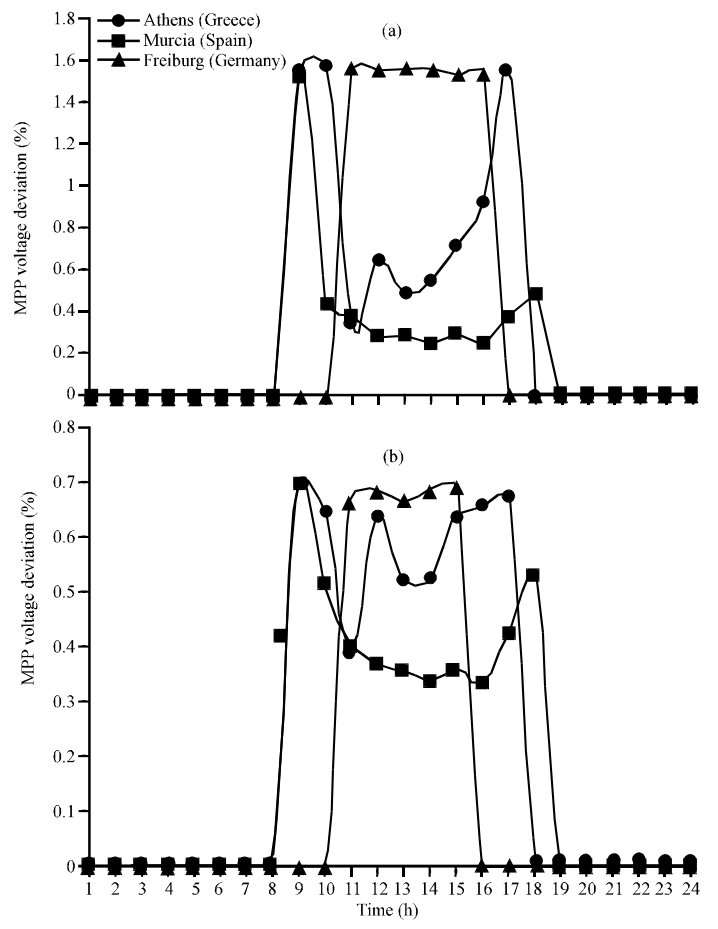

Fig. 10: The voltage deviation between the MPP points of the proposed and the conventional MPPT Methods during a Winter day at various sites in Europe for; a) a PV inverter with galvanic isolation and $\mathrm{b}$ ) a transformer less $\mathrm{PV}$ inverter

Method compared to the injected energy using the conventional MPPT Methods during the same winter day at various sites in Europe for the two PV inverters under study is shown in Fig. 9.

Each of these sites is characterized by a different solar irradiation potential. It is observed that the energy gain is increased when the solar irradiance incident on the PV array is low (e.g., during the sunrise and sunset hours) where both PV inverters operate at low DC input power levels. Compared to the PV inverter with galvanic isolation (Fig. 9a), the energy increment is lower in case of the transformer less PV inverter (Fig. 9b), since its power conversion efficiency is less dependent on the operating DC input voltage value.

The variation of the voltage deviation between the MPP points of the proposed and the conventional MPPT methods (i.e., points A and B in Fig. 5) during the same winter day at various sites in Europe is showed in Fig. 10.

The minimum voltage deviation developed in case of a PV inverter with galvanic isolation is $0.25 \%$. In case that a digital PWM generator is used in the PV inverter control unit, this voltage deviation corresponds to a 9 bit resolution of the PV inverter PWM control signal.

\section{CONCLUSION}

The energy injected into the electric grid by a PV installation depends on the amount of power extracted from the PV power source and the efficient processing of this power by the $\mathrm{DC} / \mathrm{AC}$ inverter. In this study, two new techniques are presented for the optimal design of a PV inverter power section, output filter and MPPT control strategy.

The influences of the electric grid regulations and standards as well as the PV array operational characteristics on the design of grid connected PV inverters have been considered. The proposed methods have been applied for the optimal design of PV inverters installed at various sites in Europe.

The simulation results indicate that the optimal values of the $\mathrm{PV}$ inverter design (decision) variables depend on the PV inverter specifications (i.e., power rating, nominal output voltage, etc.), the technical and economic characteristics of the components used to build the PV inverter and the meteorological conditions prevailing at the installation area.

The simultaneous application of these methods for the design of a PV inverter enables the maximization of the PV energy injected into the electric grid by the optimized PV installation, thereby increasing the earnings achieved by the installed PV capacity.

\section{REFERENCES}

Araujo, S.V., P. Zacharias and R. Mallwitz, 2010. Highly efficient single-phase transformerless inverters for grid-connected photovoltaic systems. IEEE Trans. Ind. Electron., 57: 3118-3128.

Balachandran, S. and F.C.Y. Lee, 1981. Algorithms for power converter design optimization. IEEE Trans. Aerosp. Electron. Sys., 17: 422-432.

Biela, J., U. Badstuebner and J.W. Kolar, 2009. Design of a 5 - $\mathrm{kW}, 1-\mathrm{U}, 10-\mathrm{kW} / \mathrm{dm} 3$ resonant DC-DC converter for telecom applications. IEEE Trans. Power Electron., 24: 1701-1710.

Blaabjerg, F., F. Iov, T. Kerekes and R. Teodorescu, 2010. Trends in power electronics and control of renewable energy systems. Proceedings of the 14th International Power Electronics and Motion Control Conference (EPE/PEMC), September 6-8, 2010, Institute of Energy Technology, Aalborg University, Aalborg East, Denmark, pp: 1-19. 
Campbell, M., J. Blunden, E. Smeloff and P. Aschenbrenner, 2009. Minimizing utility-scale PV power plant LCOE through the use of high capacity factor configurations. Proceedings of the 34th IEEE Photovoltaic Specialists Conference, June 7-12, 2009, SunPower Corporation, San Jose, CA, USA, pp: 421-426.

Cecati, C., F. Ciancetta and P. Siano, 2010. A multilevel inverter for photovoltaic systems with fuzzy $\log$ ic control. IEEE Trans. Ind. Electron., 57: 4115-4125.

Figueres, E., G. Garcera, J. Sandia, F. Gonzalez-Espin and J.C. Rubio, 2009. Sensitivity study of the dynamics of threephase photovoltaic inverters with an LCL grid filter. IEEE Trans. Ind. Electron., 56: 706-717.

Floricau, D., G. Gateau, A. Leredde and R. Teodorescu, 2009. The efficiency of three-level active NPC converter for different PWM strategies. Proceedings of the 13th European Conference on Power Electronics and Applications, October 6, 2009, Faculty of Electronic Engineering, University Politechnical of Bucharest, Bucharest, Romania, pp: $1-9$.

Giesler, B., 2010. String vs. Central inverters: Dimension of the inverter. Proceedings of the Photon's 1st PV Inverter Conference, April 2010, Stuttgart, Germany, pp: 1-23.

Guerrero, J.M., F. Blaabjerg, T. Zhelev, K. Hemmes and E. Monmasson et al., 2010. Distributed generation: Toward a new energy paradigm. IEEE Ind. Electron. Mag., 4: 52-64.

Kerekes, T., R. Teodorescu, M. Liserre and R. Mastromauro, 2008. A. Dell'Aquila, MPPT algorithm for voltage controlled PV inverters. Proceedings of the 11th International Conference on Optimization of Electrical and Electronic Equipment, May 22-24, 2008, Institute of Energy Technology, Aalborg University, Aalborg, pp: 427-432.

Kerekes, T., R. Teodorescu, P. Rodriguez, G. Vazquez and E. Aldabas, 2011. A new high-efficiency single-phase transformerless PV inverter topology. IEEE Trans. Ind. Electron., 58: 184-191.

Kjaer, S.B., J.K. Pedersen and F. Blaabjerg, 2005. A review of single-phase grid-connected inverters for photovoltaic modules. IEEE Trans. Ind. Appl, 41: $1292-1306$.

Koutroulis, E. and F. Blaabjerg, 2011. Design optimization of grid-connected PV inverters. 26th Annual IEEE Applied Power Electronics Conference and Exposition, March 6-11, 2011, Technical University of Crete, Chania, Greece, pp: 691-698.
Liserre, M., F. Blaabjerg and S. Hansen, 2005. Design and control of an LCL-filter-based three-phase active rectifier. IEEE Trans. Ind. Appl., 41: $1281-1291$.

Lorenzo, E., 1994. Solar electricity: Engineering of photovoltaic systems. 1st Edn., Earthscan Publications Ltd., Progensa, ISBN-10: 8486505550 , pp: 316.

Ma, L., X. Jin, T. Kerekes, M. Liserre, R. Teodorescu and P. Rodriguez, 2009. The PWM strategies of gridconnected distributed generation active NPC inverters. Porceedings of the IEEE Energy Conversion Congress and Exposition, September 2024, 2009, Beijing Jiao Tong University, Beijing, China, pp: $920-927$.

Neugebauer, T.C. and D.J. Perreault, 2003. Computeraided optimization of DC/DC converters for automotive applications. IEEE Trans. Power Electron., 18: $775-783$.

Nge, C.L., O.M. Midtgard, L. Norum and T.O. Saetre, 2009. Power loss analysis for single phase gridconnected PV inverters. Porceedings of the 31 st International Telecommunications Energy Conference, October 18-22, 2009, Faculty of Engineering and Science, University of Agder, Grimstad, Norway, pp: 1-5.

Parayandeh, A., C. Pang and A. Prodic, 2009. Digitally controlled low-power DC-DC converter with instantaneous on-line efficiency optimization. Porceedings of the 24th Annual IEEE Applied Power Electronics Conference and Exposition, February 1519, 2009, ECE Deptartment, University of Toronto, Toronto, ON, pp: 159-163.

Patel, H. and V. Agarwal, 2009. MPPT scheme for a PV-fed single-phase single-stage grid-connected inverter operating in CCM with only one current sensor. IEEE Trans. Energy Convers., 24: 256-263.

Pattnaik, S.K. and K.K. Mahapatra, 2010. Power loss estimation for PWM and soft-switching inverter using RDCLI. Porceedings of the International Multi Conference of Engineers and Computer Scientists, March 17-19, 2010, Hong Kong, pp: 1401-1406.

Pulikanti, S.R., M.S.A. Dahidah and V.G. Agelidis, 2008. SHEPWM switching strategies for active neutral point clamped multilevel converters. Porceedings of the Australasian Universities Power Engineering Conference, December 14-17, 2009, School of Electronics and Information Engineering, University of Sydney, Sydney, NSW, pp: $1-7$. 
Rahim, N.A. and J. Selvaraj, 2010. Multistring five-level inverter with novel PWM control scheme for PV application. IEEE Trans. Ind. Electron., 57: 21111-21123.

Ristow, A., M. Begovic, A. Pregelj and A. Rohatgi, 2008. Development of a methodology for improving photovoltaic inverter reliability. IEEE Trans. Ind. Electron., 55: 2581-2592.
Vazquez, G., T. Kerekes, A. Rolan, D. Aguilar, A. Luna and G. Azevedo, 2009. Losses and CMV evaluation in transformerless grid-connected PV topologies. IEEE Int. Symp. Ind. Electron. 10.1109/ISIE. 2009.5213296.

Xiao, H., S. Xie, Y. Chen and R. Huang, 2011. An optimized transformerless photovoltaic grid connected inverter. IEEE Trans. Ind. Electron., 58: 1887-1895. 